\title{
Urina humana como atraente natural de Anastrepha spp. (Diptera: Tephritidae) em pomar de goiaba (Psidium guajava L.)
}

\author{
Human urine used as a natural attractive of Anastrepha spp. \\ (Diptera: Tephritidae) in guava (Psidium guajava) orchard
}

\author{
Francisco Roberto de Azevedo ${ }^{1 *}$, Jorge Anderson Guimarães ${ }^{2}$, Claudiomar Cícero de Souza ${ }^{3}$, \\ Cicero Antonio Mariano dos Santos ${ }^{3}$, Daniel Rodrigues Nere ${ }^{3}$, Eridiane da Silva Moura ${ }^{3}$, \\ Raul Azevedo ${ }^{3}$, Flávio Batista da Silva ${ }^{3}$
}

\begin{abstract}
RESUMO: Objetivando avaliar a eficiência da urina humana como atraente alimentar no monitoramento e/ou controle de Anastrepha spp. em pomar de goiaba, foram realizadas três pesquisas em Barbalha, Ceará. Na primeira, de 16 de março a 16 de abril de 2012, foram utilizados suco de goiaba e urina pura de doadores com idades de 20, 25, 30,35 e 40 anos. Na segunda, conduzida de 25 de abril a 10 de junho de 2013, foram utilizados suco de goiaba e urina de doador de 30 anos nas concentraçóes de 10, 30, 50, 70 e 100\% e períodos de envelhecimento de 3,7, 14 e 21 dias. Já na terceira pesquisa, de 27 de junho a 04 de julho de 2013, foram testadas urina masculina, feminina e a mistura delas. Os atraentes foram instalados em armadilhas McPhail em blocos ao acaso, contendo $400 \mathrm{~mL}$ do atrativo. Semanalmente, as armadilhas foram examinadas e as moscas coletadas levadas ao laboratório de Entomologia da Universidade Federal do Cariri, Campus do Crato, para triagem e contagem. Foi verificado que os adultos de Anastrepha spp. têm preferência por urinas de doadores jovens. O tempo de exposiçáo da urina humana no campo influencia na captura, tendo sido observado que aos sete dias de exposição houve aumento na captura de adultos de Anastrepha spp. A urina masculina é mais eficiente do que a feminina, tornando-a ineficiente quando ocorre a mistura. Portanto, ela pode substituir o suco de goiaba no manejo agroecológico de moscas-das-frutas em goiabeiras de pequeno produtor, pois, além de gratuito, é de fácil aquisição e aplicação.
\end{abstract}

PALAVRAS-CHAVE: Tephritidae; Psidium; monitoramento; ureia.

\begin{abstract}
Aiming to evaluate the efficiency of human urine in comparison to guava juice in monitoring and/or control of Anastrepha spp. in guava orchard, three research studies were conducted in Barbalha, Ceará, Brazil. The first one, from 16 March to 16 April 2012, using guava juice and pure urine donors aged 20, 25, 30, 35, and 40 years old. The second one was conducted from April 25 to June 10, 2013, using guava juice and urine of a 30 year old donor testing concentrations of 10 , $30,50,70$, and $100 \%$ human urine, with aging periods of 3,7 , 4,14 , and 21 days. The last research occurred from 27 June to 4 July 2013, and tested the influence of male and female urine, and both mixed. Five McPhail traps were installed in a randomized block design, using $400 \mathrm{~mL}$ of the attractive in each one. The traps were examined once a week, and the flies were collected and taken to the laboratory of entomology of the Universidade Federal do Crato, Crato campus, for screening and counting. The adults of Anastrepha spp. prefer for urine from young donors and those that are more concentrated. The aging of the human urine (seven days) increases the capture of adults of Anastrepha spp. The male urine is more efficient than females' urine, making it inefficient when mixing. Therefore, urine can substitute the guava juice in agroecologic management programs in small producers' guava orchards. It's free, easy to acquire and to apply.
\end{abstract}

KEYWORDS: Tephritidae; Psidium; monitoring; urea.

\footnotetext{
'Laboratório de Entomologia Agrícola, Centro de Ciências Agrárias e da Biodiversidade, Universidade Federal do Cariri - Crato (CE), Brasil.

'Laboratório de Entomologia, Embrapa Hortaliças - Brasília (DF), Brasil.

${ }^{3}$ Laboratório de Entomologia Agrícola, Universidade Federal do Cariri - Crato (CE), Brasil.

*Autor correspondente: razevedo@ufc.br

Recebido em: $11 / 11 / 2013$. Aceito em: 28/10/2015
} 


\section{INTRODUÇÃO}

As moscas-das-frutas são consideradas as pragas mais importantes na cultura da goiaba, tanto pelos danos diretos que causam aos frutos, como do ponto de vista quarentenário, quando a produção se destina à exportação (SouZA Filho; Costa, 2009). As larvas se alimentam da polpa dos frutos, tornando-os impróprios para o consumo ou para a industrialização, causando sérios prejuízos (Araujo; Zucchi, 2003).

O monitoramento é uma atividade essencial para o correto manejo dessa praga, e geralmente é realizado com o uso de armadilhas tipo McPhail, contendo proteína hidrolisada de milho como atraente. No entanto, esse tipo de monitoramento tem se mostrado inviável para os pequenos produtores da região, devido ao alto custo da proteína hidrolisada e por sua dificuldade de comercializaçáo. Por isso, têm-se estudado sistemas de monitoramento com atrativos alternativos e mais baratos, como os sucos de frutas, ureia, melaço, urina e esterco de galinha (Rodríguez et al., 2000).

No município do Crato, Ceará, Azevedo et al. (2012) verificaram que o suco de goiaba, feito com frutas podres e/ou sem padrão para comercializaçáo, pode ser utilizado no monitoramento das moscas-das-frutas em substituição à proteína hidrolisada e que a urina humana também pode ser uma alternativa viável de baixa tecnologia para os agricultores familiares. A urina humana é uma fonte de amônia (PiñERo et al., 2003) e, por isso, pode ser utilizada como atraente alimentar de moscas-das-frutas em pomares comerciais de frutas, porém, sua eficiência tem sido variável nos diferentes trabalhos realizados (Нedström, 1988; Piñero et al., 2002; Piñero et al., 2003; Aluja; Pińero 2004; Canal et al., 2010).

Assim, o objetivo deste trabalho foi avaliar a eficiência da urina humana em substituiçáo ao suco de goiaba, a fim de buscar alternativas para o monitoramento e/ou controle de Anastrepha spp. em pequenas propriedades produtoras de goiaba de mesa do Cariri cearense.

\section{MATERIAL E MÉTODOS}

\section{Local de estudo}

As pesquisas foram conduzidas em um pomar comercial de goiaba (Psidium guajava L.) com dez anos de idade, com frutos da variedade Paluma, na fase de frutificação e maturação dos frutos, localizado a $07^{\circ} 17^{\prime} 18^{\prime \prime} \mathrm{S}$ e 390 20'57'W, altitude de 459,2 m em Barbalha, Ceará.

As goiabeiras foram plantadas no espaçamento de 6,0 x 5,0 m, totalizando 0,5 ha de área efetiva. Foram adotadas todas as práticas culturais rotineiras, como adubaçōes, capinas e irrigaçôes, sem haver, no entanto, aplicaçôes de inseticidas químicos para o controle das pragas da goiabeira.

\section{Efeito da idade do doador da urina sobre a atração de Anastrepha spp.}

A pesquisa foi conduzida no período de 16 de março a 16 de abril de 2012, considerando como unidade experimental uma armadilha McPhail de plástico transparente, com a base amarela, disposta em blocos ao acaso, com 6 tratamentos e 4 repetiçóes, totalizando 24 unidades experimentais. As armadilhas foram instaladas em fileiras alternadas distantes 10 metros umas da outras, a uma altura média de 2,0 metros em local sombreado e em árvores com frutos em fase de maturação e colheita.

Os tratamentos consistiram de amostras de urinas de doadores saudáveis, com idades de 20, 25, 30, 35 e 40 anos sem diluiçáo $(100 \%)$ e suco de goiaba a $25 \%+10 \%$ de açúcar cristal como testemunha. Cada doador recebeu um recipiente plástico de dois litros devidamente esterilizado e um funil de plástico para coletar a urina dois dias em média antes da aplicação. Em cada armadilha foram colocadas $400 \mathrm{~mL}$ do atrativo. Os doadores utilizados nessa pesquisa não foram submetidos a nenhuma dieta especial, pois o objetivo da pesquisa foi utilizar a urina nas condiçóes reais nas quais um pequeno produtor de goiaba poderia utilizá-la como atrativo.

Semanalmente, as armadilhas foram examinadas e as moscas atraídas foram coletadas, utilizando uma peneira plástica de malha fina e um pincel. Os insetos capturados foram acondicionados em recipientes plásticos de $100 \mathrm{~mL}$ contendo álcool a 70\%, devidamente etiquetados com os respectivos tratamentos. Em seguida, o material foi levado ao laboratório de Entomologia da Universidade Federal do Cariri, no Crato, Ceará, para triagem e contagem. As armadilhas permaneceram instaladas no pomar durante todo o período de estudo. Apenas o atrativo alimentar era reposto uma vez por semana, durante as coletas das moscas.

Foram realizadas quatro avaliaçóes, aos 7, 14, 21 e 28 dias após a instalação das armadilhas no campo para verificar se o tempo de exposição das armadilhas afetaria a eficiência na captura das moscas, sem haver a necessidade da substituição delas.

\section{Efeito da concentração e envelhecimento da urina sobre a atração de Anastrepha spp.}

A pesquisa foi conduzida no período de 25 de abril a 10 de junho de 2013 e a unidade experimental foi uma armadilha McPhail de plástico transparente e base amarela, disposta em delineamento estatístico de blocos ao acaso em esquema fatorial $6 \times 4$ e 4 repetiçôes, totalizando 96 unidades experimentais. Os tratamentos do primeiro fator foram suco de goiaba a $25 \%+10 \%$ de açúcar cristal como testemunha e a urina do doador de 30 anos de idade nas concentraçóes de $10,30,50,70$ e $100 \%$ de urina, utilizando a mesma metodologia de aplicaçáo das urinas e coleta das moscas da pesquisa 
anterior. Já para o segundo fator foram coletadas as moscas aos 3,7, 14 e 21 dias após a colocação das urinas e suco de goiaba nas armadilhas instaladas no campo que correspondeu ao período de envelhecimento dos atrativos.

\section{Efeito do sexo do doador da urina sobre a atração de Anastrepha spp.}

A pesquisa foi conduzida no período de 27 de junho a 04 de julho de 2013 e a unidade experimental também foi uma armadilha McPhail plástica transparente de base amarela, disposta em delineamento estatístico de blocos ao acaso com 4 tratamentos e 5 repetiçóes, totalizando 20 unidades experimentais. Os tratamentos foram suco de goiaba a $25 \%+10 \%$ de açúcar cristal como testemunha e as urinas masculina e feminina a $100 \%$ de concentração e a mistura $(50 \%$ masculina $+50 \%$ feminina). Foi utilizada a urina do doador de \pm 30 anos das pesquisas anteriores e de uma doadora da mesma idade para a urina feminina.

Foi utilizada a mesma metodologia de instalação das armadilhas no pomar, aplicaçáo das urinas nas armadilhas e coleta das moscas atraídas das pesquisas anteriores.

\section{Avaliação da relação custo/benefício}

A relação custo/beneficio é um indicador que relaciona os benefícios de uma pesquisa, expressos em termos monetários, e os seus custos, também expressos em termos monetários. Tanto os benefícios como os custos devem ser expressos em valores vigentes (FEDER, 2003). Foram avaliados os preços da polpa do suco de goiaba e sua aplicaçáo no controle de moscas-das-frutas em comparaçáo ao uso da urina humana para as condiçóes de um pomar de um pequeno produtor do Cariri cearense.

\section{Análise estatística}

Os dados obtidos nos experimentos foram submetidos à análise de variância, comparando-se as médias pelo teste de
Tukey a 5\% de probabilidade. Para efeito de significância, os dados foram transformados em $\sqrt{ } \mathrm{x}+0,5$.

\section{RESULTADOS E DISCUSSÃO}

\section{Efeito da idade do doador da urina sobre a atração de Anastrepha spp.}

Observou-se que, aos 7 dias após a instalação das armadilhas no pomar, houve maior captura de moscas-das-frutas nas armadilhas contendo urinas provenientes de doadores com idades de 25 e 30 anos, as quais não diferiram da testemunha (Tabela 1). Assim sendo, essas urinas têm eficiência similar ao suco de goiaba para o monitoramento e/ou controle de Anastrepha spp. em programas de manejo agroecológico dessas pragas em pomares de goiaba de pequeno e médio produtor nesse período de avaliação.

A urina do doador com 40 anos de idade foi a que atraiu o menor número de moscas-das-frutas nos levantamentos (Tabela 1). LANGLey (1971) verificou que existe uma variação na composição química da urina humana devido a fatores como idade, qualidade e quantidade do alimento ingerido.

Aos 14 dias, observou-se maior preferência das moscas pela urina do doador de 30 anos. Novamente, a urina do doador de 40 anos foi a menos preferida e, nesse período, não diferiu estatisticamente do suco de goiaba e das demais urinas (Tabela 1). Ou seja, a partir desse período de exposição dos atraentes no campo, as moscas passaram a preferir mais as urinas ao próprio suco da fruta hospedeira.

O doador de 30 anos, apesar de apresentar uma faixa etária intermediária entre os doadores jovens (20 e 25 anos) e maduros (35 e 40 anos), apresenta uma alimentação saudável. Esse fator possivelmente favoreceu o doador a excretar uma urina com ótimos teores de ureia e amônia para as moscas (Tabela 2). A influência da alimentação na excreção de urina mais atrativa para moscas-das-frutas também foi constatada por Piñero et al. (2003) e Aluja; Piñero (2004) ao utilizarem

Tabela 1. Número médio de adultos de Anastrepha spp. capturados em armadilhas McPhail iscadas com suco de goiaba e urinas de doadores com 20, 25, 30, 35 e 40 anos de idade, dos sete aos 28 dias após a instalação das armadilhas no pomar de goiaba. Barbalha, Ceará, 2012.

\begin{tabular}{|c|c|c|c|c|c|}
\hline \multirow{2}{*}{ Tratamentos } & \multicolumn{4}{|c|}{ Dias após a instalação das armadilhas } & \multirow{2}{*}{ Total } \\
\hline & 7 & 14 & 21 & 28 & \\
\hline Suco de goiaba & $78,50 * a$ & $24,75 b$ & $47,50 \mathrm{ab}$ & $08,25 \mathrm{~ns}$ & $159,00 \mathrm{bc}$ \\
\hline Doador de 20 anos & $26,25 a b$ & $76,75 a b$ & $31,00 \mathrm{ab}$ & $50,50 \mathrm{~ns}$ & $184,50 \mathrm{bc}$ \\
\hline Doador de 25 anos & $60,50 \mathrm{a}$ & $54,50 \mathrm{ab}$ & $50,75 a b$ & $28,50 \mathrm{~ns}$ & $194,25 b$ \\
\hline Doador de 30 anos & $62,00 \mathrm{a}$ & 156,75 a & $118,25 \mathrm{a}$ & $83,75 \mathrm{~ns}$ & $420,75 \mathrm{a}$ \\
\hline Doador de 35 anos & $36,50 a b$ & $79,50 \mathrm{ab}$ & $86,25 a b$ & $44,00 \mathrm{~ns}$ & $246,25 b$ \\
\hline Doador de 40 anos & $06,00 \mathrm{~b}$ & $16,25 b$ & $19,75 b$ & $08,75 \mathrm{~ns}$ & $50,75 \mathrm{c}$ \\
\hline C.V. (\%) & 31,09 & 32,87 & 36,13 & 46,42 & 19,96 \\
\hline
\end{tabular}

Médias seguidas pela mesma letra nas colunas não diferem estatisticamente entre si pelo teste de Tukey ( $p>0,05)$; ${ }^{*}$ dados transformados em $\sqrt{ } \mathrm{x}$ + 0,5; ns: não significativo; C.V.: coeficiente de variação. 
urina de um doador com 26 anos de idade, submetido a uma dieta rigorosa livre de café, bebidas alcoólicas, suplementos vitamínicos, condimentos e cigarros.

Aos 21 dias após a instalação das armadilhas no campo, comprovou-se que a urina do doador de 30 anos é a mais preferida entre as demais, enquanto que a do doador de 40 anos foi a menos preferida pelas moscas (Tabela 1). Já as demais urinas demonstraram eficiências similares ao suco de goiaba. Nesse período as moscas não discriminavam mais entre o suco de goiaba e as urinas dos doadores.

Aos 28 dias não houve diferença estatística entre os tratamentos avaliados (Tabela 1). Possivelmente, isso ocorreu devido a um maior período de exposição das armadilhas no pomar, com excesso de poeira e estágio mais avançado de decomposição dos atraentes, tornando-as menos atrativas para as moscas-das-frutas.

Levando-se em consideração o total das quatro avaliaçôes realizadas no pomar, constatou-se que a urina humana mais adequada para uso na captura de moscas-das-frutas do gênero Anastrepha foi a do doador de 30 anos de idade, seguida das urinas dos doadores de 35 e 25 anos, respectivamente. Observa-se, portanto, que náo importa só a idade do doador, mas também a sua alimentação.

De acordo com Bell et al. (1961), um indivíduo saudável deverá apresentar na composição química de sua urina $20 \mathrm{a}$ $30 \mathrm{~g} / 100 \mathrm{~mL}$ de ureia e 6 a $47 \mu \mathrm{mol} / \mathrm{L}$ de amônia. Conforme resultados dos exames das urinas dos doadores (Tabela 2), percebe-se que os doadores de 25 e 40 anos estão com teores de ureia abaixo dos limites saudáveis. Já o doador de 30 anos apresentou teores mais elevados desse composto, indicando ser a urina mais preferida pelas moscas para alimentaçấo e/ou oviposiçáo. As urinas dos doadores de 20 e 35 anos apresentaram teores dentro dos limites de uma pessoa saudável. Com relação à amônia, todos os doadores apresentaram teores dentro do limite favorável de uma pessoa saudável.

Quantitativamente foram verificadas diferenças entre os quatro períodos de avaliaçóes, isso indica que foram capturados diferentes números de adultos de Anastrepha spp. em diferentes épocas, com os maiores índices de captura ocorrendo aos 14 e 21 dias após a instalação das armadilhas no pomar de goiaba (Fig. 1), quando a população de moscas aumentou devido à presença de um maior número de frutos hospedeiros

Tabela 2. Teores de ureia e amônia das urinas dos doadores obtidos por meio do método enzimático automatizado. Crato, Ceará, 2013.

\begin{tabular}{lcc} 
Doadores & \multicolumn{1}{c}{ Ureia } & Amônia \\
\hline 20 anos & $23,07 \mathrm{~g} / 100 \mathrm{~mL}$ & $26,45 \mu \mathrm{mol} / \mathrm{L}$ \\
\hline 25 anos & $16,00 \mathrm{~g} / 100 \mathrm{~mL}$ & $22,94 \mu \mathrm{mol} / \mathrm{L}$ \\
\hline 30 anos & $26,00 \mathrm{~g} / 100 \mathrm{~mL}$ & $25,29 \mu \mathrm{mol} / \mathrm{L}$ \\
\hline 35 anos & $20,02 \mathrm{~g} / 100 \mathrm{~mL}$ & $23,71 \mu \mathrm{mol} / \mathrm{L}$ \\
\hline 40 anos & $15,00 \mathrm{~g} / 100 \mathrm{~mL}$ & $20,14 \mu \mathrm{mol} / \mathrm{L}$ \\
\hline
\end{tabular}

Fonte: Laboratório Vicente Lemos. maduros. Somente o suco de goiaba e a urina do doador de 25 anos capturaram um maior número de moscas aos 7 dias, chegando a atingir um total de 314 e 242 indivíduos, respectivamente. Os valores do índice de moscas/armadilha/semana oscilaram entre 6 e 157 indivíduos nos diferentes períodos e nos diferentes tratamentos, no entanto, ocorreram capturas em todos os tratamentos. A população se manteve sempre alta e dentro do nível de dano econômico, que é de sete moscas/ armadilha/semana para a cultura da goiaba.

Considerando-se o número total de adultos de Anastrepha spp. nos quatro períodos de avaliaçóes, percebeu-se que a maior captura ocorreu na armadilha contendo urina do doador de 30 anos, na qual foram constatados 1.683 indivíduos, seguida da urina de 35 anos com 985 indivíduos. As urinas dos doadores de 20 e 25 anos capturaram números próximos do suco de goiaba, que foi de 636 indivíduos, no entanto, a urina do doador de 40 anos foi a que capturou o menor número, com apenas 203 indivíduos (Fig. 2).

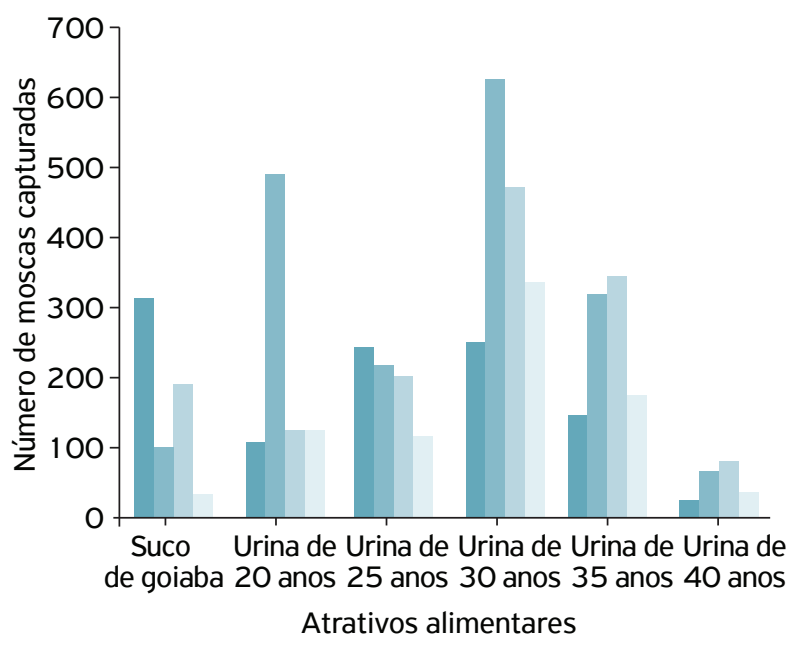

-1a avaliação $\llbracket 2 a$ avaliação 3a avaliação 4a avaliação

Figura 1. Diferenças de capturas de adultos de Anastrepha spp. entre os quatro períodos de avaliações após a instalação das armadilhas no pomar de goiaba. Barbalha, Ceará, 2012.

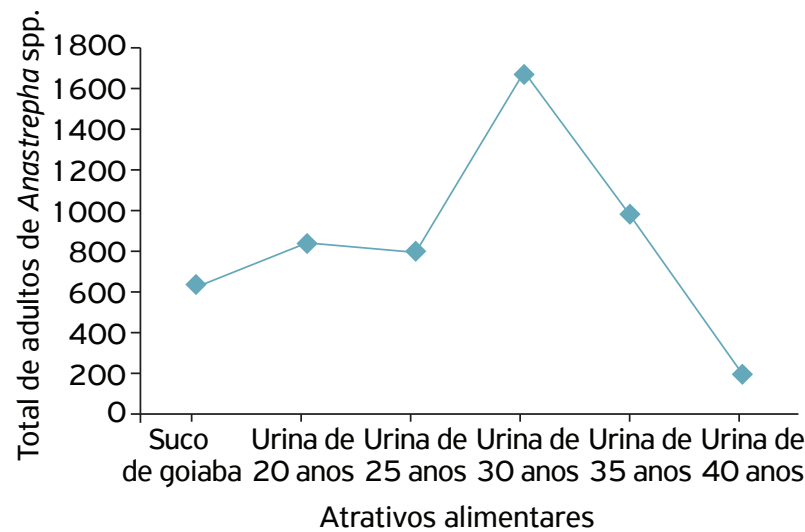

Figura 2. Total de adultos de Anastrepha spp. nos quatro períodos de avaliações submetidos aos atraentes alimentares em pomar de goiaba. Barbalha, Ceará, 2012. 
Portanto, quantitativamente, as urinas dos doadores jovens têm eficiências semelhantes à do suco de goiaba, enquanto que aquelas de doadores com idade acima dos 30 anos são melhores, principalmente quando eles têm uma boa alimentação. A partir dos 40 anos, há uma reduçáo nas propriedades quali e quantitativa da urina no que diz respeito à atração dos adultos.

Para os pequenos produtores do Cariri a utilização do suco de goiaba no monitoramento e/ou controle dessa praga, apesar de barato, tem certo custo, pelo qual a utilização de substâncias com teores de amônia e ureia, como a urina humana, pode ser uma alternativa ecológica e economicamente viável, pois ele terá custo zero na sua plantação, assim como reutilizará os seus dejetos líquidos, evitando contaminação do meio rural.

$\mathrm{Na}$ presente pesquisa, foi capturado um total de 5.126 moscas adultas em um período de 4 semanas. Para o pequeno produtor que já está acostumado com perdas de frutos de goiaba com o ataque de moscas-das-frutas, significa uma grande vantagem, pois essas fêmeas capturadas nas armadilhas não irão ovipositar nos frutos e acarretar prejuízos econômicos aos produtores.

\section{Efeito da concentração e envelhecimento da urina sobre a atração de Anastrepha spp.}

Em todos os atraentes testados ocorreu aumento nas capturas de moscas aos sete dias de exposiçáo no campo, todavia náo acontecendo de modo linear em todos eles (Tabela 3). Esses resultados estão de acordo com os de CANAL et al. (2010). No entanto, a maior captura se deu quando foi utilizada urina a $100 \%$, capturando-se um total de 145 moscas adultas. Esses mesmos autores verificaram que ao elevar a concentração da urina até $70 \%$, que foi o maior valor, capturou-se um maior número de adultos de $A$. obliqua em pomar de manga (Mangifera indica L.), enquanto que nas concentraçóes menores das urinas as capturas foram menores. A partir daí a população reduziu consideravelmente até os 21 dias $(52,6)$, com valor próximo ao do período de 3 dias $(41,3)$. Ao utilizar fermento de pão como atraente alimentar, SALLes (1999) observou maior captura total (115) de A. fraterculus aos oito dias de envelhecimento em pomar de pêssego, período similar ao da presente pesquisa.

O suco de goiaba e as urinas a 10 e $30 \%$ não diferiram estaticamente entre si aos 14 e 21 dias de envelhecimento e capturaram o menor número de moscas adultas quando comparados com os períodos de 3 e 7 dias (Tabela 3).

A partir da concentração da urina a $50 \%$ houve um aumento na captura das moscas, principalmente aos 7 dias de envelhecimento, seguido das capturas aos 14 dias. Pelos resultados obtidos nesta pesquisa, recomenda-se então utilizar a urina mais concentrada (100\%). Contudo, Hedström (1988) constatou que a urina humana a uma concentração de 50\%, usada sem reposição, capturou dez vezes mais indivíduos de A. striata Schiner e $A$. obliqua do que a levedura tórula em pomar de goiaba na Costa Rica.

Piñero et al. (2003) utilizaram em seus estudos urina a 50\% de concentração e Aluja; Piñero (2004) avaliaram concentraçôes de 12,5; 25 e 50\% de urina. As concentraçóes utilizadas por esses autores foram selecionadas para evitar uma possível diminuição na atração da isca por concentraçôes altas de amônia, o que não foi observado na presente pesquisa, pois a urina mais concentrada capturou um maior número de moscas.

Percebe-se que a urina mesmo a média $(30 \%)$ ou baixa (10\%) concentração desempenha uma eficiência similar ao suco de goiaba em todos os períodos de envelhecimento. PIÑERo $e t$ al. (2003) encontraram resultados similares, afirmando que na maioria dos experimentos desenvolvidos não há diferenças na captura das moscas quando testadas concentraçóes decrescentes de urina $(50 ; 25$ e 12,5\%). Isso tem implicaçóes práticas muito importantes, pois o pequeno produtor poderá abastecer um maior número de armadilhas com uma pequena quantidade de urina humana, assim como também poderá aumentar o número de armadilhas por área se o interesse é realizar um monitoramento massivo no pomar e promover o controle das moscas por meio da sua retirada da área de cultivo.

PIÑERo et al. (2002) acreditaram que a urina humana é mais atrativa do que a proteína hidrolisada de milho, devido à presença de compostos voláteis, já que a amônia presente na urina é utilizada pelas moscas-das-frutas para localização de alimento e locais para oviposição (Hull; CRIB, 2001).

Tabela 3. Número médio de adultos de Anastrepha spp. capturados em armadilhas McPhail iscadas com suco de goiaba e urinas com diferentes concentrações e períodos de envelhecimento em pomar de goiaba. Barbalha, Ceará, 2013.

\begin{tabular}{|c|c|c|c|c|c|c|c|}
\hline \multirow{2}{*}{ Dias } & \multicolumn{6}{|c|}{ Tratamentos } & \multirow{2}{*}{ Total } \\
\hline & Suco & U10\% & U30\% & U50\% & U70\% & U100\% & \\
\hline 3 & $7,0 * \mathrm{Aa}$ & $6 \mathrm{Aa}$ & 7,5 Aa & $5,25 \mathrm{Ba}$ & 7,0 Ba & $8,5 \mathrm{Ca}$ & 41,3 \\
\hline 7 & $10,5 \mathrm{Ac}$ & $13,5 \mathrm{Ac}$ & $10,0 \mathrm{Ac}$ & $36,0 \mathrm{Ab}$ & $23,3 \mathrm{Abc}$ & $51,8 \mathrm{Aa}$ & 145,1 \\
\hline 14 & $6,5 \mathrm{Ab}$ & $2,0 \mathrm{Ab}$ & $3,8 \mathrm{Ab}$ & $16,0 \mathrm{Bb}$ & $12,0 \mathrm{ABb}$ & $36,0 \mathrm{Ba}$ & 76,3 \\
\hline 21 & $5,5 \mathrm{Ab}$ & $1,3 \mathrm{Ab}$ & $3,8 \mathrm{Ab}$ & 8,0 Bab & $20,5 \mathrm{Aa}$ & 13,5 Cab & 52,6 \\
\hline C.V. (\%) & 24,34 & & & & & & \\
\hline
\end{tabular}

U: concentrações das urinas humanas; médias seguidas pela mesma letra maiúscula nas colunas e minúscula nas linhas não diferem estatisticamente entre si pelo teste de Tukey $(p>0,05)$; *dados transformados em $\sqrt{x}+0,5$; C.V.: coeficiente de variação. 
Da mesma forma, Morales et al. (1999), ao avaliarem diferentes atraentes para a captura da mosca do abacaxi Melanoloma viatrix Hendel (Diptera: Richardiidae), concluíram que a maior taxa de captura ocorre quando se utilizam os dejetos de suínos e humanos, tanto puros ou com componentes de amônia como a urina. Heath (1993) relatou evidências de que a amônia e seus compostos desempenham um importante papel na atraçáo olfativa de moscas-das-frutas. Ao contrário de outros insetos, fêmeas adultas de Diptera exigem uma dieta proteica para que ocorra a oogênese (WHEELER 1996), sendo que a amônia é percebida pelos tefritídeos como uma sugestão para fontes de alimentos ricos em proteínas (LópEZ-GuILLÉN et al. 2010), o que explica a maior quantidade de moscas capturadas em urina humana em relação ao suco de goiaba.

PIÑERo et al. (2003) fizeram alusão à razão custo-benefício do uso de urina humana e recomendaram seu uso para pequenos produtores, pois, apesar de capturar menos fêmeas em períodos curtos de tempo, tem a vantagem de poder ser obtida no próprio campo/residência e ser utilizada com armadilhas feitas com materiais recicláveis, como garrafas PET, diminuindo, assim, o ônus com a compra de iscas ou armadilhas.

\section{Efeito do sexo do doador da urina sobre a atração de Anastrepha spp.}

Após sete dias de exposição dos atraentes no pomar, observou-se que a urina masculina capturou um maior número de adultos de Anastrepha spp. do que a feminina (Tabela 4). Já com a mistura delas não houve diferença estatística nas capturas entre si. A urina masculina não diferiu estatisticamente do suco de goiaba na captura das moscas (Tabela 4). Em um pomar de manga, nesse mesmo período de exposição, CANAL et al. (2010) verificaram também que a urina masculina a $70 \%$ foi mais eficiente do que a urina feminina nessa

Tabela 4. Número médio de adultos de Anastrepha spp. capturados em armadilhas McPhail iscadas com suco de goiaba e urinas masculina e feminina em pomar de goiaba após sete dias de aplicação. Barbalha, Ceará, 2013.

\begin{tabular}{lc} 
Tratamentos & Moscas capturadas* \\
\hline Suco de goiaba & $42,0 \mathrm{a}$ \\
\hline Urina masculina & $38,2 \mathrm{a}$ \\
\hline Urina feminina & $28,0 \mathrm{~b}$ \\
\hline Mistura & $15,0 \mathrm{~b}$ \\
\hline C.V. (\%) & 30,23 \\
\hline
\end{tabular}

Médias seguidas de mesma letra na coluna não difere estatisticamente entre si pelo teste de Tukey ( $p>0,05)$; ${ }^{*}$ dados transformados; C.V.: coeficiente de variação. mesma porcentagem e que a mistura a 50\%, pois foram capturas nas armadilhas 200, 120 e 80 indivíduos de $A$. obliqua, respectivamente. Na presente pesquisa foram utilizadas urinas masculinas e femininas a 100\% de concentração.

As espécies identificadas no pomar de goiaba do município de Barbalha, Ceará, onde foi realizada a pesquisa foram: A. obliqua, A. sororcula e A. zenildae. AzEvedo et al. (2010), ao realizarem um estudo da análise faunística e flutuação populacional de moscas-das-frutas em pomares comerciais de goiaba no Crato, Juazeiro do Norte e Barbalha, constataram que $A$. zenildae, $A$. sororcula, $A$. fraterculus, $A$. obliqua e Ceratitis capitata foram as moscas-das-frutas associadas à goiaba, sendo que $A$. zenildae, $A$. sororcula e $A$. obliqua foram dominantes e constantes na regiáo estudada, corroborando, assim, os resultados da presente pesquisa.

\section{Avaliação da relação custo/benefício}

$\mathrm{Na}$ presente pesquisa, buscou-se encontrar um atrativo alimentar natural e a um custo zero para o pequeno produtor controlar essas pragas, como no caso da urina humana, que é de fácil aquisição e obtém-se diariamente.

No pomar em estudo foram utilizadas 140 armadilhas iscadas com $400 \mathrm{~mL}$ do suco de goiaba nos três ensaios. Conforme dados da Tabela 5, podemos observar que houve um gasto semanal do pequeno produtor da ordem de $\mathrm{R} \$ 280,00$ quando se utilizou o suco de goiaba. Se multiplicarmos esse valor por 4 semanas, ele terá um custo de $\mathrm{R} \$ 1.120,00$ mensais contra zero de custo utilizando a urina humana.

\section{CONCLUSÕES}

Os adultos de Anastrepha spp. têm preferência por urinas de doadores jovens.

Quanto mais concentrada a urina humana, maior a captura de adultos de Anastrepha spp. para as condiçóes do Cariri cearense.

$\mathrm{O}$ envelhecimento da urina humana aos sete dias de exposição aumenta a captura de adultos de Anastrepha spp.

A urina masculina é mais eficiente do que a feminina na captura de moscas-das-frutas no Cariri cearense, tornando-a ineficiente quando ocorre a mistura.

A urina humana pode substituir o suco de goiaba em programas de manejo agroecológico de moscas-das-frutas em goiabeiras de pequeno produtor, pois, além de gratuito, é de fácil aquisição e aplicação no pomar.

Tabela 5. Valores em reais e custo de aplicação em 0,5 hectare de um pomar de goiaba utilizando suco de goiaba comparado com a urina humana. Barbalha, Ceará, 2012.

\begin{tabular}{lcccc} 
Produtos & Valor unitário (R\$) & $\mathrm{mL} / \mathrm{L}$ & Litros do atrativo/0,5 ha & Custo da aplicação/semana (R\$) \\
Suco de goiaba & $2,50(100 \mathrm{~mL}$ de polpa) & 200 & 56 & 280,00 \\
\hline Urina humana & - & 100 & 56 & - \\
\hline
\end{tabular}




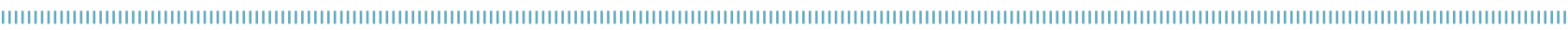
REFERÊNCIAS

ALUJA, M.; PIÑERO, J. Testing human urine as a low-tech bait for Anastrepha spp. (Diptera: Tephritidae) in small guava, mango, sapodilla and grapefruit orchards. Florida Entomologist, v.87, n. 1, p. 41-50, 2004.

ARAUJO, E.L.; ZUCCHI, R.A. Moscas-das-frutas (Diptera: Tephritidae) em goiaba (Psidium guajava), em Mossoró RN. Arquivos do Instituto Biológico, v.70, n.1, p.73-77, 2003.

AZEVEDO, F.R.; GUIMARÃES, J.A.; SIMPLÍCIO, A.A.F.; SANTOS, H.R. Análise faunística e flutuação populacional de moscas-dasfrutas (Diptera: Tephritidae) em pomares comerciais de goiaba na região do Cariri cearense. Arquivos do Instituto Biológico, v.77, n. 1, p.33-41, 2010.

AZEVEDO, F.R.; GURGEL, L.S.; SANTOS, M.L.L.; SILVA, F.B.; MOURA, M.A.R.; NERE, D.R. Eficácia de armadilhas e atrativos alimentares alternativos na captura de moscas-da-fruta em pomar de goiaba. Arquivos do Instituto Biológico, v.79, n.3, p.343-352, 2012.

BELL, G.H.; DAVIDSON, J.N.; SCARBOROUGH, H. Textbook of Physiology and Biochemistry. Ediburgh: The Williams and Wilkins Company, $1961.72 \mathrm{p}$.

CANAL, N.A.; PÉREZ, M.L.O.; GONZALES, L.F. La orina humana como atrayente natural de Anastrepha obliqua (Diptera: Tephritidae). Revista Colombiana de Entomologia, v.36, n. 1, p.31-37, 2010

FEDER. FUNDO EUROPEU DE DESENVOLVIMENTO REGIONAL. Manual de análise de custos e benefícios dos projetos de investimentos. Brasília: MAPA; 2003. 154 p.

HEATH, R.R.; EPSKY, N.D.; LANDOLT, P.J.; SIVINSKI, J. Development of attractants for monitoring Caribbean fruit flies (Diptera:Tephritidae). Florida Entomologist, v.76, n.2, p. 233-244, 1993.

HEDSTRÖM, I. Una sustancia natural en la captura de moscas de la fruta del género Anastrepha Schiner (Diptera: Tephritidae). Revista de Biología Tropical, v.36, n.2A, p.269-272, 1988.

HULL, C.D.; CRIBB, B.W. Olfaction in the Queensland fruit fly, Bactrocera tryoni. I: identification of olfactory receptor neuron types responding to environmental odors. Journal Chemical Ecology, v.27, n.5, p.871-887, 2001.
LANGLEY, L.L. Physiology of Man. New York: Van Nostrand Reinhold Company, $1971.771 \mathrm{p}$.

LÓPEZ-GUILLÉN, G.; TOLEDO, J.; ROJAS, J.C. Response of Anastrepha obliqua (Diptera: Tephritidae) to fruit odors and protein-based lures in field trials. Florida Entomologist, v.93, n.2, p.317-318, 2010.

MORALES, J.G.; POLANCO, E.D.; PEÑA, R.R. Reconocimiento de la fauna insectil, enemigo naturales y evaluación de atrayentes de Melanoloma viatrix. Información Tecnológica, 10. CORPOICA; 1999. $4 \mathrm{p}$.

PIÑERO, J.; ALUJA, M.; EQUIHUA, M.; OJEDA M. M. Feeding history, age and sex influence the response of four economically important Anastrepha species (Diptera: Tephritidae) to human urine and hydrolyzed protein. Folia Entomologica Mexicana, v.41, n.3, 283-296, 2002.

PIÑERO, J.; ALUJA, M.; VÁZQUEZ, A.; EQUIHUA, M.; VARÓN, J. Human urine and chicken feces as fruit fly (Diptera: Tephritidae) attractants for resource-poor fruit growers. Journal of Economic Entomology, v.96, n.2, p.334-340, 2003.

RODRIGUEZ, G.G.; MARK, P.D.; SILVA-ACUÑA, R.; GONZALEZ, E.; MILANO, E. Evaluacion de trampas y formulaciones atrayentes para la captura de la mosca de la guayaba, Anastrepha striata Schiner (Diptera: Tephritidae) en Santa Bárbara, Monagas, Venezuela. Boletín de Entomología Venezolana, v.15, n.1, p.49$60,2000$.

SALLES, L.A. Efeito do envelhecimento e da decomposição do atrativo na captura de adultos de Anastrepha fraterculus (Wied.) (Diptera: Tephritidae). Revista Brasileira de Agrociência, v.5 n.2, p.147-148,1999.

SOUZA FILHO, M.F.; COSTA, V.A. Manejo integrado de pragas na goiabeira. In: NATALE, W.; ROZANE, D.E.; SOUZA, H.A.; AMORIM, D.A. (Eds). Cultura da goiaba do plantio a comercialização. Jaboticabal: FCAV/CAPES/CNPq/FAPESP/FUNDUNESP; 2009. Cap. 13, p.327-348.

WHEELER, D. The role of nourishment in oogenesis. Annual Review of Entomology, v.41, n.1 p.407-431, 1996. 